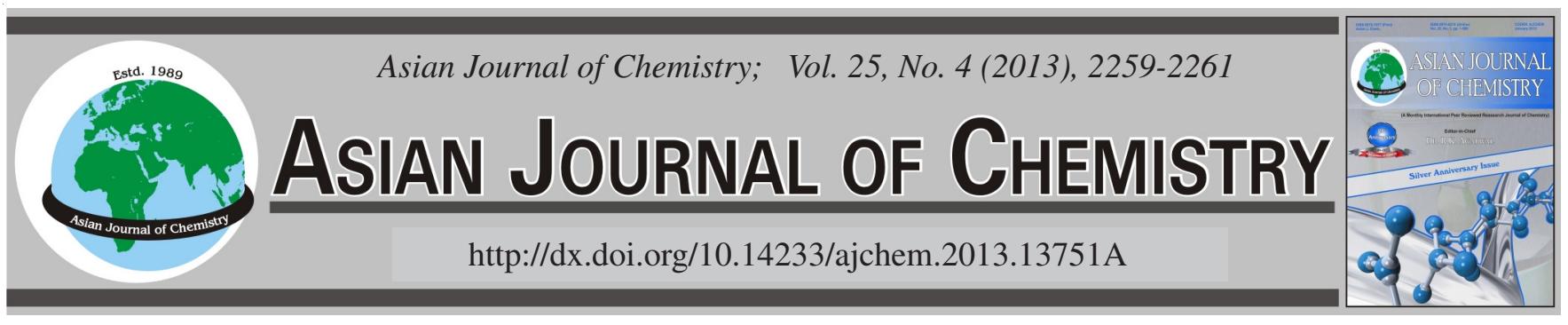

\title{
Effective Parameters onto Swelling Capacity of Biosuperabsorbent Based on Acrylonitrile-Sucrose
}

\author{
Fatemeh Soleimani ${ }^{1, *}$, Mohammad SAdEGHI $^{2}$, Hadis Shasevari ${ }^{1}$, Arezoo Soleimani ${ }^{1}$ and Hossein SAdeghi $^{3}$
}

\author{
${ }^{1}$ Young Researchers Club, Khorramabad Branch, Islamic Azad University, Khorramabd, Iran \\ ${ }^{2}$ Department of Chemistry, Science Faculty, Arak Branch, Islamic Azad University, Arak, Iran \\ ${ }^{3}$ Department of Chemistry, Science Faculty, Khorramabad Branch, Islamic Azad University, Khorramabad, Iran
}

*Corresponding author: Fax: +98 861 3670017; Tel: +98 916 1613256; E-mail: fatisoleymani@yahoo.com

After synthesis of a superabsorbent hydrogel based on sucrose and polyacrylonitrile, the effect of reaction variables such as concentration of $\mathrm{NaOH}$ and hydrolysis time and temperature were systematically optimized to achieve a hydrogel with swelling capacity as high as possible. Under the optimized conditions, maximum capacity of swelling in distilled water was found to be $610 \mathrm{~g} / \mathrm{g}$. Finally, the swelling kinetics of the hydrogels with various particle sizes was also investigated.

Key Words: Sucrose, Polyacrylonitrile, Hydrogel, Superabsorbent, Swelling behaviour.

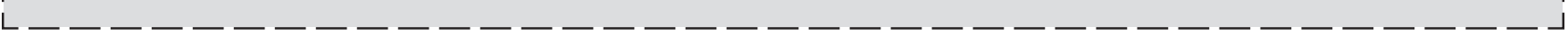

\section{INTRODUCTION}

Hydrogels are hydrophilic three-dimensional polymer networks capable of absorbing a large volume of water or other biological fluid ${ }^{1}$. Hydrogels resemble the natural living tissue more than any other class of synthetic biomaterials. Thus hydrogels have found widespread application in different areas, e.g., as materials for contact lenses and artificial skin, wound dressing, protein separation, membranes for biosensors and devices for the controlled release of drugs ${ }^{2-6}$.

Stimuli-sensitive hydrogels have the capability to change their swelling behaviour, permeability or mechanical strength in response to external stimuli, such as small changes in $\mathrm{pH}$, ionic strength, temperature and electromagnetic radiation ${ }^{7-10}$.

The principal requirement of any controlled release system is that the release profile and rate are controlled. Controlled or sustained release drugs provide many advantages in comparison with conventional forms including reduced side effects. When the drug concentration kept at effective levels in plasma, improved utilization of drug and decreases the dosing times. Drug delivery systems based on hydrogels have been extensively explored to achieve the higher concentration of drugs in the specific region or tissue and the controlled release profile for extended time periods ${ }^{11-14}$. The well-known method for the synthesis of superabsorbent hydrogels is free radical polymerization technique ${ }^{15-18}$. The first industrial superabsorbent hydrogel, hydrolyzed sucrose-g-polyacrylonitrile (HSPAN), was synthesized using this method ${ }^{19}$. Radical polymerization has several disadvantages. Reproducibility of this method is poor and there is little control over the grafting process, so that the molecular weight distribution is polydisperse. In addition, the necessity for toxic and/or expensive monomer and crosslinker are another disadvantages of free radical polymerization reactions. The toxicity of the crosslinker has adverse effects on the biocompatibility of the obtained materials ${ }^{20}$. After the development of the H-sucrose-g-polyacrylonitrile hydrogel, for the first time, Fanta et al. ${ }^{21}$ with development a new method, tried to synthesis of H-sucroseg-polyacrylonitrile superabsorbent hydrogel. They hydrolyzed the physical mixture of starch and polyacrylonitrile. The initially formed oxygen-carbon bonds between starch hydroxyls and nitrile groups of the polyacrylonitrile chains remain as crosslinking sites.

To the best of our knowledge, there is no published report on the synthesis and investigation of effective parameters onto superabsorbing hydrogel via alkaline hydrolysis of sucrosepolyacrylonitrile physical mixture. Hence, the objectives of this study were to synthesize of a superabsorbent hydrogel and investigation of the swelling properties of these hydrogels as a function of polyacrylonitrile amount, $\mathrm{NaOH}$ concentration and $\mathrm{pH}$ values were investigated.

\section{EXPERIMENTAL}

The disaccharide sucrose was purchased from Merck Chemical Co. (Germany). Polyacrylonitrile was synthesized through a method mentioned in the literature ${ }^{22}$. The drug, verapamil hydrochloride, was received from Aldrich Chemical 
Co. Double distilled water was used for the hydrogel preparation and swelling measurements.

\section{RESULTS AND DISCUSSION}

Effect of $\mathrm{NaOH}$ concentration on swelling capacity: The effect of concentration of $\mathrm{NaOH}$ on water absorbency of hydrogel is shown in Fig. 1. It is obvious that the higher the $\mathrm{NaOH}$ concentration leads to more carboxamide and carboxylate groups. The concentrations of $\mathrm{NaOH}$ higher than 7 wt \%, however, lead to low-swelling superabsorbents. This swellingloss can be related to residual (excess) alkaline, which was not removed (e.g., neutralized), after completion of hydrolysis. The excess cations shield the carboxylate anions, so that the main anion-anion repulsive forces are eliminated and a less expanded networks of the hydrogel being able to uptake and retain lower quantities of the aqueous solution. In addition, a higher crosslinked structure formed at higher $\mathrm{OH}^{-}$concentration. Furthermore, alkaline degradation of the polysaccharide part of network can be another reason of the swelling decrease in highly concentrated alkaline hydrolytic media.

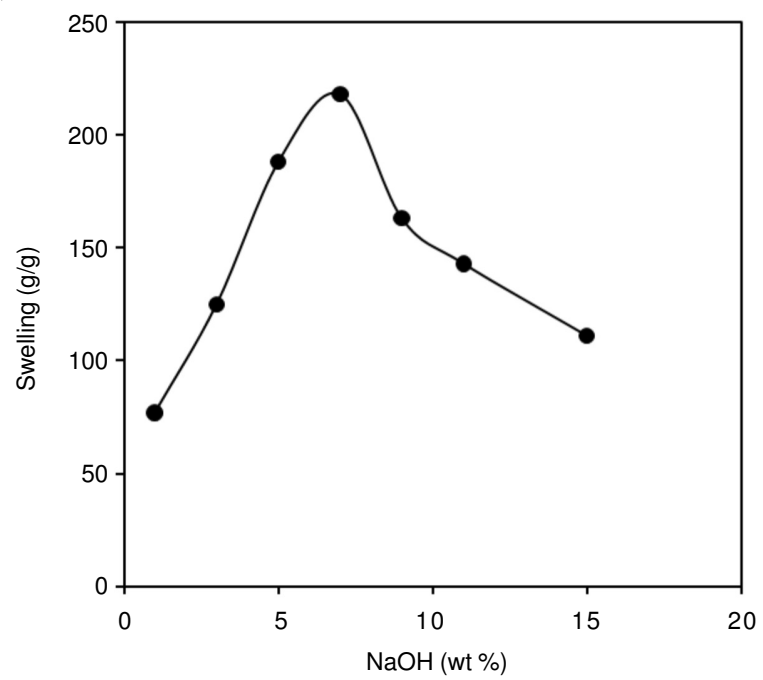

Fig. 1. Effect of $\mathrm{NaOH}$ concentration on swelling capacity of H-sucroseg-polyacrylonitrile hydrogel

Effect of polyacrylonitrile/sucrose weight ratio on swelling capacity: Different superabsorbent hydrogels with various polyacrylonitrile/sucrose weight ratio were synthesized by changing the amount of polyacrylonitrile $(0.25-1.50 \mathrm{~g})$ and sucrose (0.25-1.50 g). According to Fig. 2, the maximum swelling capacity $(323 \mathrm{~g} / \mathrm{g})$ was achieved at $1.50 \mathrm{~g}$ of polyacrylonitrile. The higher the polyacrylonitrile amount leads to more carboxamide and carboxylate groups generated from alkaline hydrolysis. However, lower absorbency was achieved when a further amount of polyacrylonitrile (> $1.50 \mathrm{~g})$ was applied. This can be attributed to the formation of more crosslinks at higher polyacrylonitrile amount.

Effect of alkaline hydrolysis temperature: The relationship between the alkaline hydrolysis temperature and water absorbency values was studied by varying the hydrolysis temperature from $50-90{ }^{\circ} \mathrm{C}$ (Fig. 3). Higher temperature favours the kinetics of alkaline hydrolysis up to $80{ }^{\circ} \mathrm{C}$. This behaviour was confirmed by faster discoloration at higher

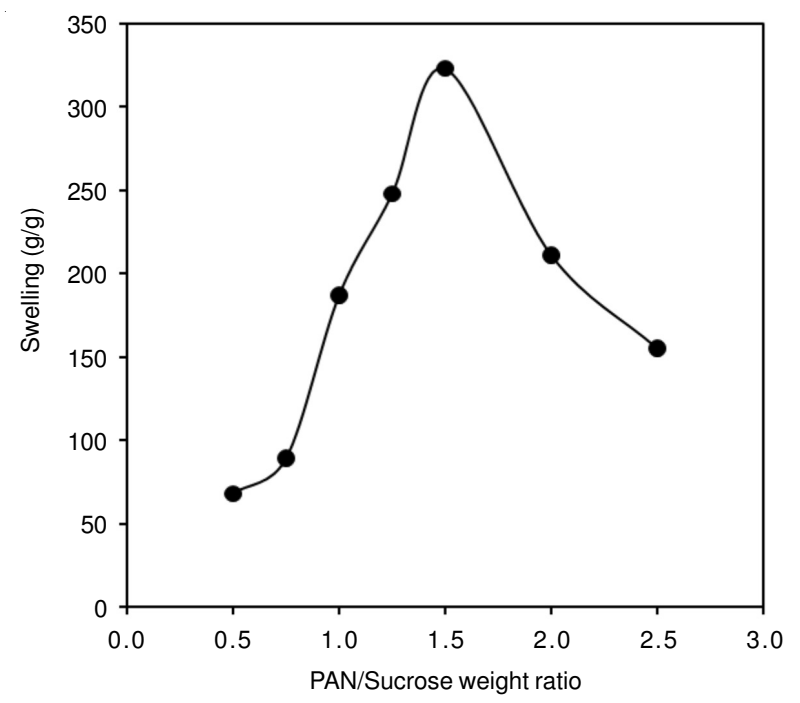

Fig. 2. Effect of PAN/sucrose weight ratio on swelling capacity of Hsucrose-g-polyacrylonitrile hydrogel

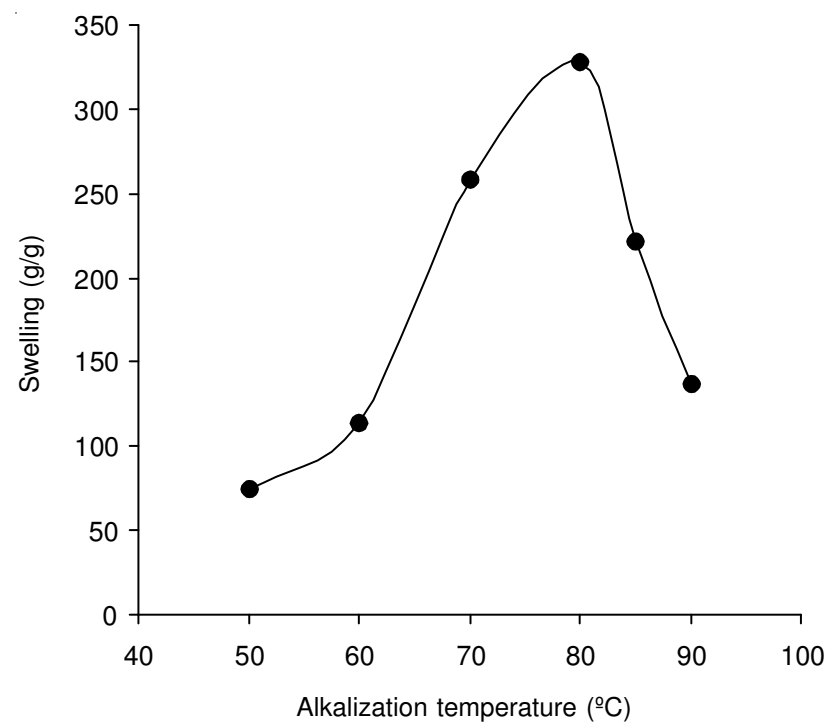

Fig. 3. Effect of alkalization temperature on swelling capacity of H-sucroseg-polyacrylonitrile hydrogel

temperatures. The temperatures higher than this value, however, in reduced swelling. This may be attributed to more crosslinked formation and alkaline degradation of the disaccharide chains of the hydrogel at higher temperatures $\left(\mathrm{T}>80^{\circ} \mathrm{C}\right)$. Similar observation has reported by Yamaguchi et al..$^{22}$ in the case of the hydrogels of starch sulfate-g-polyacrylonitrile.

Kinetics of swelling: In practical applications, not only a higher swelling capacity is required, but also a higher swelling rate is needed. Buchholz et al. ${ }^{1}$ has suggested that the swelling kinetics for the superabsorbents is significantly influenced by factors such as swelling capacity, size distribution of powder particles, specific size area and composition of polymer. Fig. 4 represents the dynamic swelling behaviour of sucrose-polyacrylonitrile superabsorbent samples with various particle sizes in water. Initially, the rate of water uptake sharply increases and then begins to level off. The time required to reach the equilibrium swelling capacity was achieved after ca. $25 \mathrm{~min}$. According to "Voigt-based model", the swelling rate can be described by the following equation ${ }^{20}$ : 


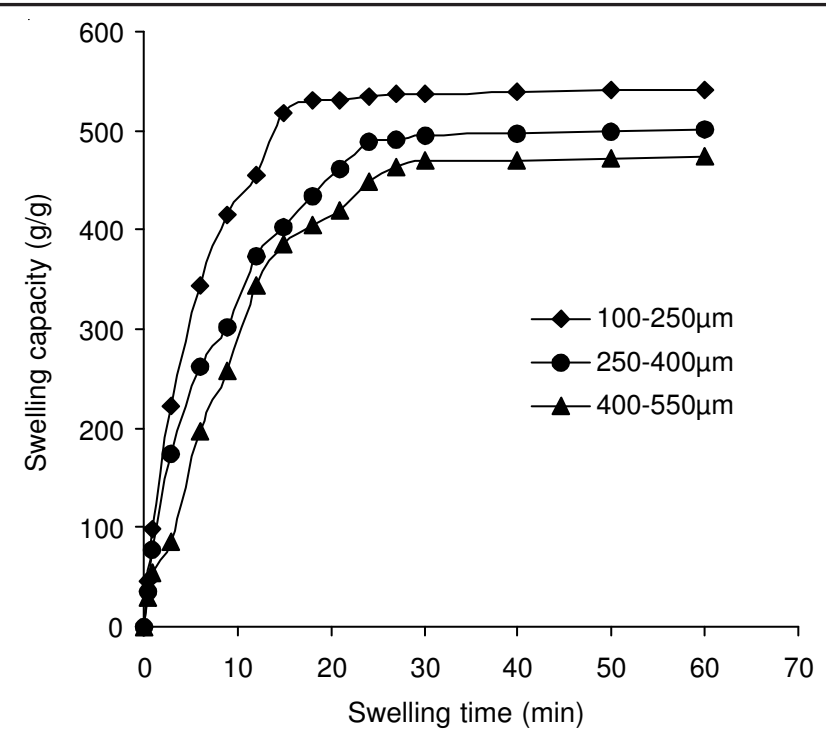

Fig. 4. Representative swelling kinetics of H-sucrose-g-polyacrylonitrile superabsorbent hydrogel with various particle sizes

$$
\mathrm{S}_{\mathrm{t}}=\mathrm{S}_{\mathrm{e}}\left(1-\mathrm{e}^{\mathrm{t} / \tau}\right)
$$

where $S_{t}(g / g)$ is swelling at time $t, S_{e}$ is equilibrium swelling (power parameter, $\mathrm{g} / \mathrm{g}$ ), $\mathrm{t}$ is time (min) for swell"ing $\mathrm{S}_{\mathrm{t}}$ and $\tau$ (min) stand for "rate parameter". The rate parameters for superabsorbent are found to be 5.8, 10.7 and $11.6 \mathrm{~min}$ for superabsorbent with 100-250, 250-400 and 400-550 $\mu \mathrm{m}$, respectively. It is well-known that the swelling kinetics for the superabsorbent polymers is significantly influenced by particle size of the absorbents ${ }^{21}$. With a lower the particle size, a higher rate of water uptake is observed. An increase in the rate of absorption would be expected from the increase in surface area with decreasing particle size of hydrogel. Additionally, the ultimate degree of absorption increased as the particle size became smaller. This is attributed to more water being held in the volume between the particles.

\section{Conclusion}

After synthesis of the superabsorbent hydrogel, sucrosepolyacrylonitrile, through alkaline hydrolysis of sucrose-polyacrylonitrile physical mixture, we were attempted to be optimized the reaction conditions for obtaining hydrogels with higher swelling values. So, the maximum water absorbency $(325 \mathrm{~g} / \mathrm{g})$ was achieved under the optimum conditions that found to be: alkalization at $80{ }^{\circ} \mathrm{C}, \mathrm{NaOH} 7 \mathrm{wt} \%$, polyacrylonitrile/sucrose weight ratio 1.5 . Finally, dynamic swelling kinetics of hydrogels shows that the rate of absorbency is increased with decreasing the particle size of superabsorbing samples.

\section{REFERENCES}

1. F.L. Buchholz and A.T. Graham, Modern Superabsorbent Polymer Technology, New York: Wiley (1997).

2. I.Y. Galaev and B. Mattiasson, Trends Biotechnol., 17, 335 (1999).

3. H. He, X. Cao and L.J. Lee, J. Control. Rel., 95, 391 (2004).

4. D. Kuckling, A. Ritcher and K.F. Arndt, Macromol. Mater. Eng., 288, 144 (2003).

5. M.E. Byrne, K. Park and N.A. Peppas, Adv. Drug. Deliv. Rev., 54, 149 (2002).

6. K. Szczubialka, A. Karewicz, L. Moczek, K.Zomerska and M. Nowakowska, e-Polymers, No. 031 (2006).

7. H.K. Ju, S.Y. Kim and Y.M. Lee, Polymer, 42, 6851 (2001).

8. N.A. Peppas, P. Bures, W. Leobandung and W. Ichikawa, Eur. J. Pharm. Biopharm., 50, 27 (2000).

9. O. Hirasa, S. Ito, A. Yamauchi, S. Fujishige and H. Ichijo, Polymer Gels, Fundamentals and Biomedical Application, Plenum Press, New York, p. 247 (1991).

10. H.K. Ju, S.Y. Kim, S.J. Kim and Y.M. Lee, J. Appl. Polym. Sci., 83, 1128 (2002).

11. V. Raghavendra, V. Kulkarni, S.M. Setty and B. Sa, Macromolecules, 47, 520 (2010).

12. H.Y. Zhou, Y.P. Zhang, W.F. Zhang and X. Guang, Carbohydr. Polym., 83, 1643 (2011).

13. S. Hua, H. Yang, W. Wang and A. Wang, Appl. Clay Sci., 50, 112 (2010).

14. K. Hori, C. Sotozono, J. Hamuro, K. Yamasaki, Y. Kimura, M. Ozeki Y. Tabata and S. Kinoshita, J. Control. Rel., 118, 169 (2007).

15. M. Yazdani-Pedram, J. Retuert and R. Quijada, Macromol. Chem. Phys., 201, 923 (2000).

16. Y. Sugahara and O. Takahisa, J. Appl. Polym. Sci., 82, 1437 (2001).

17. G.M. Patel and H.C. Trivedi, Eur. Polym. J., 35, 201 (1999).

18. S. Silong and L. Rahman, J. Appl. Polym. Sci., 76, 516 (2000).

19. United States Department of Agriculture, US Patent, 3981100 (1961).

20. W.E. Hennink and C.F. van Nostrum, Adv. Drug Del. Rev., 54, 13 (2002).

21. G.F. Fanta, R.C. Burr and M.W. Doane, ACS Symp. Ser., 187, 195 (1982).

22. M. Yamaguchi, H. Watamoto and M. Sakamoto, Carbohydr. Polym., 9, 15 (1988). 